\title{
Los jesuitas y la Inquisición al sur del Perú en tiempos de Felipe II. Entre los discursos de poder y las formas de dominación del territorio
}

\author{
The Jesuits and the Inquisition at the south of Perú in the times of Philip the $2^{\text {nd }}$. \\ Between the speech of power \\ and the domination of the territory
}

Federico Sartori ${ }^{*}$

DOI: http://dx.doi.org/10.31057/2314.3908.v6.n2.22953

Resumen: Este trabajo se propone indagar acerca del funcionamiento de la justicia inquisitorial del Tribunal Limeño, desde su instauración en 1569 y hasta pocos años después del giro al siglo XVII, en las regiones del Tucumán, Río de la Plata y Paraguay; así como algunos aspectos de la relación establecida entre la Inquisición y los jesuitas actuantes en la región. Con este fin, se interroga sobre los orígenes de estas relaciones entre la Compañía de Jesús y la Inquisición, instituciones de muy distintos objetivos y modos de actuación, aun cuando ambas estuviesen fuertemente ligadas a la Monarquía española. Y de modo más específico, qué carácter tuvo este vínculo en las gobernaciones al sur del Perú, donde la Compañía de Jesús había puesto uno de sus principales focos de evangelización. Quiénes y a través de qué instrumentos legales participaron los jesuitas del ejercicio de la justicia inquisitorial y, cómo fue su actuación en este sentido; estas son las principales preguntas de esta investigación.

Palabras Clave: Jesuitas - Inquisición - Paraguay - Poder - Territorio

Abstract: This work intends to inquire about the functioning of the Inquisitorial Justice of the Limeño Tribunal, since it was established in 1569 until a few years after the turning into to the XVII century, in the regions of Tucumán, Rio de la Plata and

*Licenciado y doctor en Historia (UNC). E-mail: federicosartori@gmail.com

3 Federico Sartori Moyano. Los jesuitas y la Inquisición al sur del Perú... 4-26. 
Paraguay; as well as some aspects of the set-up established relationship between the Inquisition and the Jesuits in the region. To achieve this aim, we question the origins of these relations between the Society of Jesus and the Inquisition, institutions of very different aims and modes of action, even though both were strongly linked to the Spanish Monarchy. And more specifically, what was the nature of this link in the governorates of southern Peru, where the Society of Jesus had placed one of its main centres of evangelization. Who and through what legal instruments the Jesuits participated in the exercise of inquisitorial justice and, as was their performance in this sense; these are the main questions of this research.

Key Words: Jesuits - Inquisition - Paraguay - Power - Territory

Recibido: 27 de octubre de 2017.

Evaluado: 4 de febrero de 2018. 


\section{Introducción}

En este trabajo nos proponemos indagar acerca del funcionamiento de la justicia inquisitorial del Tribunal Limeño, desde su instauración en 1569 y hasta pocos años después del giro al siglo XVII, en las regiones del Tucumán, Río de la Plata y Paraguay; así como algunos aspectos de la relación establecida entre la Inquisición y los jesuitas actuantes en la región.

La historiografía sobre la presencia de la Compañía de Jesús en este amplio territorio para los siglos XVI y XVII es muy extensa y quizás, por el relevante papel que desempeñó la Orden en la conquista y colonización de la región, sea uno de aspectos más estudiados de la historia colonial sudamericana. Sin embargo, las efectivas relaciones establecidas entre la Compañía y el poder inquisitorial emanado del Tribunal limeño, es todavía poco conocido ${ }^{1}$. De este modo, el objetivo principal de esta investigación ha sido reconstruir esta particular trama histórica.

Con este fin, nos interrogamos acerca de los orígenes de estas relaciones entre la Compañía y la Inquisición, instituciones de muy distintos objetivos y modos de actuación, aun cuando ambas estuviesen fuertemente ligadas a la Monarquía española. Y de modo más específico, nos preguntamos, qué carácter tuvo este vínculo en las gobernaciones al sur del Perú, donde la Compañía de Jesús había puesto uno de sus principales focos de evangelización. Quiénes y a través de qué instrumentos legales participaron los jesuitas del ejercicio de la justicia inquisitorial y, cómo fue su actuacuión en este sentido; estas son las principales preguntas que nos guiaron a través de la reconstrucción de esta historia.

Para ello nos valimos de fuentes diversas. Sin embargo, teniendo en cuenta que el eje de la investigación es el poder inquisitorial y su ejercicio, utilizamos fundamentalmente de fuentes inquisitoriales. Es harto sabido que la documentación emanada de todos los Tribunales del Santo Oficio español (no solo de los americanos) fue destruida en gran parte con el correr de los siglos tras la abolición de la Inquisición. Las causas de esta destrucción son muy diversas y responden a distintos contextos, pero lo cierto es que hoy estas pérdidas, junto a su profusa dispersión, hacen de la búsqueda heurística un camino de Teseo pero de escasos hilos. Más aún si nuestra mirada está puesta en los primeros tiempos después de la instauración de los Tribunales.

Para el caso peruano, después de la llegada de Cerezuela a Lima en 1570, nombrado primer inquisidor del Perú un año antes, sabemos que fueron estableciéndose lentamente diversos comisariatos en todas las ciudades que integraban el Virreinato, cuya jursidcción compartía el Tribunal. Pero gran parte de la documentación de estos ministros delegados, tanto la localizada en sus respectivos comisariatos como la enviada al Tribunal, ha desaparecido en gran parte; aunque con algunas extraordinarias exepciones, como el caso del pequeño 'archivo' de los comisarios radicados en Córdoba del Tucumán. Por ello hemos intentado recabar información de estos primeros ministros, y su acción, a través de otras fuentes no emanadas del Santo Oficio.

Pensamos que esta época, marcada por una justicia inquisitorial débil dependiente de la Real Hacienda y que no alcanza a efectivizar las intenciones del Tribunal limeño ni de la Corona en esta amplísima región, podría estar mostrando una

\footnotetext{
${ }^{1}$ Vale mencionar los ya clásicos trabajos de José Toribio Medina y Boleslao Lewin para la región rioplatense. Recientemente, en el contexto del siglo XVIII se destacan las investigaciones de Marcela Aspell.
}

5 Federico Sartori Moyano. Los jesuitas y la Inquisición al sur del Perú... 4-26. 
justicia de limitado alcance pero que, sin embargo, pudo servir como instrumento de poder para otros actores con objetivos bien distintos, entre ellos, la Compañía de Jesús.

\section{Los jesuitas y la Inquisición al sur del Perú}

Después del último exilio de Francisco de Aguirre en 1570, el Tucumán todavía ofrecía visibles beneficios políticos, sociales y sobre todo económicos para quien lo gobernase, por lo que tras él siguieron Jerónimo Luis de Cabrera, Gonzalo de Abreu y Hernando de Lerma, los tres impulsores del reparto de mercedes y de pueblos de indios encomendados, y los tres también apresados por su respectivo sucesor (en el caso de Lerma, su sucesor Juan Ramírez de Velasco), en una guerra por el poder que parecía no tener fin y alcanzaba ya los estrados judiciales de la capital y hasta la Península (Moyano Aliaga, 2003). Los dos primeros muertos bajo tormento y Lerma desterrado del Perú.

Con el fin de intervenir en el proceso de conquista de este territorio surperuano, la Iglesia estableció el Obispado de La Plata en $1552^{2}$, el de Santiago de Chile en 1561, el de Tucumán en 1570. Sin embargo, tras tres infructuosos nombramientos, este último no fue efectivamente ocupado hasta 1581, cuando arribó a la ciudad de Santiago del Estero el dominico de origen lusitano fray Francisco de Victoria ${ }^{3}$.

Cuando Victoria llegó al Tucumán el panorama de la región a medias conquistada, era desolador. Bajo el sistema de encomiendas ${ }^{4}$, las poblaciones locales disminuían sensiblemente, en el marco de una nueva configuración social en donde la potencia del Imperio Español se había expandido sobre el territorio a fuerza de entradas militares, y el consecuente dominio de la tierra y la explotación de las naciones indígenas en un escenario dramático (Piana, 1992). A finales del siglo XVI, este rincón de América ha quedado como último resabio de aquella sociedad del que 'viene a valer más', cuyo valor descansaba aún en los principios medievales de la conquista por las armas.

Es por ello que, para un dominico que más parecía jesuita ${ }^{5}$, la situación de los indios en el Tucumán lo alarmaba, en una posición más humanista de la Iglesia que apoyaba a Las Casas (Mateos, 1970; Lisi, 1990; Ayrolo, 2007; Levillier, 1918; Cárcano, s/f). Hasta ese momento la Iglesia aún no había podido ingresar al territorio, y su única 'presencia' eran incontables frailes y clérigos dispersos por las villas, ciudades y fortines de la inmensa región tucumana, frontera interna con Chile y el Pacífico, Brasil y la boca atlántica rioplatense, a quienes la Corona y la Iglesia querían poner freno.

\footnotetext{
${ }^{2}$ El primitivo obispado del Tucumán fue sufragáneo del arzobispado de Lima. En 1609 pasó a depender del de Charcas y estuvo bajo su jurisdicción por más de doscientos años (Levillier, 1919).

${ }^{3}$ Victoria fue el primer obispo del Tucumán en asumir el cargo, pero el cuarto en ser nombrado.

${ }^{4}$ Los gobernadores aplicaban la justicia de manera salomónica, aplicando incluso la pena de muerte a los indios. Esto se produce en el momento inmediato de la conquista; como aparece apuntado en el trabajo de Catalán (1926); manteniéndose esta situación hasta bien entrado el siglo XVII, tal como han demostrado Bixio y González Navarro (2003). Como ha señalado Lewin, “...toda la historia colonial se caracteriza por la contradicción flagrante entre las Leyes de Indias y las sombrías prácticas de los gobernantes españoles" (1939).

${ }^{5}$ Pariente de Diego Láinez, segundo General de la Compañía de Jesús, ambos provenientes de una familia de conversos. Durante toda su administración del Obispado del Tucumán, Victoria muestra una notable inclinación hacia los intereses de la Compañía de Jesús, en detrimento de la Orden Dominica, de la cual provenía.
}

6 Federico Sartori Moyano. Los jesuitas y la Inquisición al sur del Perú... 4-26. 
Una vez en Lima, Victoria, designa al presbítero Hernando de Morillo y a Francisco de Salcedo (Avella Chafer, 1944; pp. 181-196) como vicarios y administradores eclesiásticos del Tucumán y a este último como deán (Tedesco y Crouzeilles, 2005, p. 37). El primer contacto con el gobierno tucumano será conflictivo. Victoria envía a Salcedo a Santiago del Estero con el fin de preparar su propia llegada a la diócesis tucumana. Sin embargo, una vez llegado a destino, Salcedo es repudiado por el gobernador Lerma, quien lo persigue armado, hasta Talavera, desoyendo su autoridad eclesiástica $^{6}$. Al final, Salcedo escapa y recién viaja Victoria en febrero de 1581 a Potosí, y poco más de un año después alcanza Santiago del Estero. A poco de llegar y apoyándose en una Real Cédula de 1578 crea el Cabildo eclesiástico, nombrando cuatro prebendados, a saber el Provisor Francisco Vázquez, dominico ${ }^{7}$, y a los presbíteros Diego Pedrero de Trejo, Francisco de Rojas y Juan de Quirós.

Los conflictos entre el obispo y el gobernador no solo no se apaciguan sino que tendrán para uno de ellos un final de pobreza y destierro. Sintomáticos de las tensiones en todo el territorio colonial americano, entre el poder eclesiástico y el poder civil. Decía por estos años el Arzobispo de Lima en una carta a Felipe II,

"las persecuciones que sufren los prelados, especialmente los de Popayán y Tucumán, el desprecio de la jurisdicción e inmunidad eclesiástica por varias autoridades, los abusos introducidos en el cumplimiento del Real Patronazgo, y las demasías del Virrey Don Francisco de Toledo."

En efecto, a Victoria le resultaba difícil establecer un control sobre el trato a los indios y escasamente podía establecer un programa de evangelización en la región con los pocos diezmos que ingresaban a las prebendas ${ }^{9}$. Además, los vecinos encomenderos de la diócesis se sentían perjudicados por los intentos de apaciguamiento de Victoria sobre la colonización, poniéndose abiertamente del lado de Lerma. En una carta de 1583, el Cabildo de la ciudad de Córdoba da poder a Manuel Rodríguez Guerrero, Secretario del Gobernador, para que hable en su nombre con el Virrey del Perú y el Santo Oficio de Lima,

"para que por su intermedio S. M. sea informado de las cosas de esta Gobernación, se entretenga al Señor Obispo don Fray Francisco de Victoria; a cuyo para la paz e conservación de estas Provincias y remedio de ellas..."10

\footnotetext{
${ }^{6}$ Como el deán se queja de que Lerma no salió a recibirlo cuando llegó al Tucumán, éste lo persigue y en Talavera le llega a Salcedo la orden de prisión y destierro (con desconocimiento de título de Lic. y de Deán), firmada por Lerma en agosto de 1581.

${ }^{7}$ Del mismo modo que Victoria, Vázquez tiene problemas también con la Inquisición. Fue acusado en 1578 de solicitación y de otros delitos. Tuvo que comparecer en Lima hacia 1600, y se le dio penitencia, abjuró de levi, y le fue prohibida la confesión (AHN MADRID, Inquiisción, lib. 1028, f565r a f567v).

${ }^{8}$ Carta de los Obispos al Rey (Levillier, 1919).

${ }^{9}$ AHPC; Esc. 1; Leg. 2; Exp. 1, 1589: Venta de diezmos del obispo Victoria. Escribano: Alonso Nieto de Herrera (futuro notario del Santo Oficio en Córdoba).

${ }^{10} \mathrm{La}$ voz de los sectores medios y altos de las nuevas ciudades en esta región son cambiantes de acuerdo a sus intereses. Luego de la prisión de Lerma, se vuelven contra su gestión de gobierno, como consta de la Procuración que envía el Cabildo de Córdoba a la Audiencia de Charcas en 1585, a través de Hernán Mejía Mirabal y Pedro Sotelo de Narváez quienes llevan en persona la acusación contra el Gobernador Lerma: “...por los agravios y vejaciones que esta República y vecinos de ella recibieron con su entrada...", como “...sacar los vecinos de esta ciudad para llevarlos a Salta..." (Archivo Municipal, p. 513).
}

7 Federico Sartori Moyano. Los jesuitas y la Inquisición al sur del Perú... 4-26. 
Ante semejante oposición, y contra la fuerza de las armas de Lerma, Victoria se ve obligado a abandonar el Tucumán, como relata en carta al rey:

"y viendo semejante oprobio viéndome con sólo tres sacerdotes en toda la provincia por haber prendido el gobernador a los demás y enviándolos por tierra de guerra con grillos y cadenas a Charcas, me determiné salir, huyendo con sólo dos compañeros cien leguas por tierra de guerra, por donde cincuenta pasan con gran peligro teniendo por menor inconveniente morir a manos de paganos que vivir en tanto oprobio entre cristianos vasallos de V.M." 11

Esta situación, obliga al Virreinato a enviar una hueste junto al nuevo gobernador nombrado, Juan Ramírez de Velazco ${ }^{12}$, con la orden de prisión y destierro para Lerma (Segreti, 1973, p. 27). La vuelta del obispo a Santiago del Estero no cambió la situación del conflicto entre la autoridad civil y la eclesiástica, y el nuevo gobernador será excomulgado en repetidas oportunidades por el prelado, quien tendrá asimismo una mala relación con los capitulares de los cabildos y los fiscales de la Audiencia de Charcas.

Otra preocupación de Victoria para el gobierno eclesiástico de la región tucumana, se refiere a la Inquisición. Según el Inquisidor general Gutiérrez de Ulloa en carta al Consejo de 26 de abril de 1584, el Obispo Victoria, al igual que los del Cuzco y de la Plata, había pedido ser él mismo comisario, algo que le fue denegado ${ }^{13}$. Sin embargo, junto a la autorización de los jesuitas para ingresar en la Gobernación en 1585, Victoria consigue que un miembro de la Compañía de Jesús, el padre Francisco de Angulo, sea nombrado también como Comisario del Santo Oficio de la Inquisición, dependiente de Lima ${ }^{14}$. Este nombramiento se realizó de acuerdo a la Instrucción de 1569, según la cual debía haber un Comisario por cada cabeza de Obispado y uno en cada puerto de $\operatorname{mar}^{15}$.

Las razones que tenía Victoria para solicitar con tanto énfasis la presencia de la justicia inquisitorial en su diócesis parecen haber sido varias. Por una parte el manejo de esta justicia inapelable daba un altísimo poder en el contexto local. Además, su ejercicio podía poner un cierto freno a los excesos de los frailes y curas sin control en la región, así como a la autoridad civil, cualquiera fuese su posición o rango.

\footnotetext{
${ }^{11}$ Citado por Martìnez Ruiz y Cerviño en su estudio sobre el conquistador Mejìa Mirabal (1962, p. 92).

${ }^{12}$ Dice Lewin: "Ramírez de Velasco, era un celosísimo señor feudal, que como todos los señores de esta categoría, tenía por ideal el aislamiento completo de su feudo, la autarquía completa de su gobernación (...) luchando contra la actividad comercial de Vitoria. (...) Fue Ramirez de Velasco, quizás el primero, quien estableció aduanas rigurosas en los límites de su provincia, pretendiendo interrumpir el intercambio con otras gobernaciones del virreinato" (1939, p. 76).

${ }^{13}$ Ejercicio del justicia inquisitorial ordinario aun antes de la llegada del Obispo Victoria a Santiago del Estero en 1577 (y 1589): Información contra Bartolomé Valero, vecino de Nuestra Señora de Talavera en Tucumán, hecho por el "juez eclesiástico en Santiago del Estero" (AHN CHILE, Fondo Inquisición; Simancas; Vol. 23).

${ }^{14}$ En 1585 llegan los primeros misioneros jesuitas al Tucumán, los padres Francisco de Angulo y Pedro Barzana. Ese mismo año el P. Atienza, Provincial de Perú, crea la Misión del Tucumán y nombra a Angulo Superior de la misma, quien ya era comisario del Sto. Oficio (Furlong, 1946, p. 19). El padre Barzana fundó por esos años ocho pueblos de indios y aprendió once lenguas indígenas, entre ellas el quichua, aymará, guaraní, toba, tonocoté, lule y abipón, valiéndose de ellas para la evangelización. En 1590 se publicó su "Arte de la lengua toba" y "Arte y vocabulario" de la lengua de los indios abipones y querandíes. Acompañó a Ramírez de Velasco en su "jornada” contra los Calchaquíes en 1588.
}

${ }^{15}$ AHN MADRID; Inquisición; Instrucción; lib. 32. 
Es probable que el obispo tuviese también un interés personal en el manejo de estos fueros especiales de la Iglesia. Porque al igual que otros clérigos intelectuales de origen converso residentes en América, fray Francisco de Victoria era consciente que el mejor modo de no caer jamás bajo la justicia de la Inquisición, era perteneciendo a ella (Muñoz Moraleda, 1990, pp. 171-191). Y aunque no lo consiguió, es probable que el estrecho vínculo que lo unía con el padre Francisco de Angulo y el resto de los jesuitas que ingresaron al Tucumán bajo su auspicio, le diesen en contrapartida una permanente inmunidad. Se sabe incluso que Victoria fue acusado dos veces ante la Inquisición de Lima, la primera en 1585, bajo traición de un prebendado del Tucumán nombrado por él mismo, el bachiller Diego Pedrero de Trejo, quien lo acusó de amancebamiento con Ana López de Herrera "en plena sacristía y cometía otros pecados" (Lesser, 2012, p. 82).

Un año después, en marzo de 1583, el bachiller Suárez de Rendo, acusaba a Victoria de judaizante, como hermano del portugués Diego Pérez de Acosta, un converso quemado "en efigie" por judaizante y prófugo de la Inquisición. Este último caso, alcanzó los escritorios del Consejo de la Suprema en España, pero nunca se oficializó la acusación. Es concluyente que ambas causas, bajo la mirada cómplice del Comisario del Tucumán, el padre Angulo, nunca prosperaran. Por su parte, para la Compañía de Jesús, el auspicio del Obispo es crucial para establecer la Orden en estas regiones ${ }^{16}$. A través de cuyos permisos emitidos en su favor sobre concesiones de tierras, exención de impuestos y reducción de pueblos de indios, bajo el sistema de misiones evangelizadoras, los jesuitas se asentaron en el territorio.

El obispo entendía que el único modo de integrar estas lejanas gobernaciones al circuito comercial, y de esta manera participar del orden económico y socio-político del Imperio y del resto del mundo, era a través de una interconexión regional entre el Potosí, el Tucumán y la cuenca Paraguayo-Rioplatense hacia el Atlántico. Y ante la falta de regulación legal al respecto el obispo decide en 1587 hacerlo de modo ilegal, transportando personalmente y mercaderías del Tucumán y plata no acuñada de Potosí hacia el Brasil. En esta oportunidad, la mala relación con el gobernador Ramírez de Velazco, le supondrá la prisión y posterior vuelta a España, donde morirá al poco tiempo.

Pero la presencia inquisitorial limeña en el Tucumán, conseguida por el obispo Victoria, sobrevive a su prelatura. Como parte de su gestión eclesial en el territorio, entre 1585 y 1599 la aplicación de la justicia del Santo Oficio en todas las ciudades pertenecientes a la Gobernación del Tucumán estuvo en manos de un Comisario que fuera nombrado por intermediación suya, el mencionado jesuita Angulo; quien tuvo durante catorce años jurisdicción sobre todo el Obispado tucumano, desde su sede en Santiago del Estero.

El Padre Francisco de Angulo llegó al Perú en 1581 con 43 años de edad. Jesuita andaluz de alta formación en las universidades de Granada y Salamanca obtuvo a poco de llegar a Lima el cargo de Consultor del Colegio San Pablo. Tras la petición del

\footnotetext{
${ }^{16}$ Hay una intención permanente de la Corona de enviar religiosos a las gobernaciones del sur como la Real Cédula al Virrey del Perú, con orden de enviar misioneros al Tucumán en 1588. O el viaje del fraile franciscano y 'Comisario' de su Orden para el Tucumán y Río de la Plata, Juan de Rivadeneyra, quien viajó con alrededor de treinta religiosos a fines del siglo XVI, o la Real Cédula de 1591 al Gobernador de Tucumán para que ayudase a la instalación de "doctrinas" de la Compañía de Jesús (en: (Levillier, 1919, p. 435,471 y 516$)$.
}

9 Federico Sartori Moyano. Los jesuitas y la Inquisición al sur del Perú... 4-26. 
obispo Victoria al Padre Piñas, Provincial del Perú, en el III Concilio de enviar misioneros al Tucumán, Angulo fue nombrado Superior de dicha misión, además de Comisario de la Inquisición con jurisdicción en toda la diócesis del Tucumán. Junto al padre Barzana y el Hermano Villegas, alcanzó Santiago del Estero en 1585, donde permaneció hasta 1598; pasando luego a Salta y Chuquisaca, donde murió en $1611^{17}$.

Por intermediación del padre Angulo, como comisario, y del padre Juan Romero $^{18}$, también jesuita y familiar del Santo Oficio, la Compañía de Jesús logra establecer un control sobre la justicia inquisitorial del territorio en manos de sus propios miembros hasta finales del siglo XVI, ejerciendo la persecución inquisitorial de manera irregular, pero constante sobre un objetivo claro: sacerdotes del clero segular y recular de cualquier orden, culpables de abusos contra los indios, encauzado en gran medida a través del delito de la solicitación, como se expone en el apartado siguiente ${ }^{19}$.

En 1591 hay registro de la toma de residencia del padre Angulo en la ciudad de Córdoba $^{20}$, lugar que habrá de ser nombrado como sede del provincial de la Provincia Jesuítica del Paraguay en 1608. Hasta ese momento, el padre Angulo se moverá entre esta ciudad y Santiago del Estero, ejerciendo el cargo de Comisario en toda la Gobernación $^{21}$.

Además del constante en trabajo persecutorio a miembros de la propia Iglesia, el padre Angulo utilizará los instrumentos inquisitoriales con fines políticos y como instrumentos de conflicto con otros sectores de poder, como en 1592, cuando toma preso al secretario del gobernador Juan Ramírez de Velasco ${ }^{22}$, Rodríguez Guerrero, acusándolo de profanar lugar sagrado en un combate de espadas. Logra enviarlo preso a

\footnotetext{
17 Referencias a la biografía del Padre Angulo en el Catálogo del Padre Storni (1971, 147-152). Agradezco al Dr. Carlos Page por haberme señalado esta referencia bibliográfico-documental

${ }^{18}$ En 1593 el Padre Provincial del Perú, Juan Sebastián de la Parra, pide por el Padre Fonte y envía en su lugar, como nuevo Superior del Tucumán y Paraguay, al Padre Juan Romero, de 34 años de edad quien será Superior hasta 1607, es decir, hasta la llegada de Diego de Torres y la fundación de la Provincia Jesuítica del Paraguay. Diego de Torres llevó consigo trece individuos, entre ellos a Ruiz de Montoya. Por su parte, Juan Romero queda como Maestro de Novicios en Córdoba (que nunca ejerció porque se fue a Chile a la primera congregación y de allí Buenos Aires/Europa. El primer Maestro de Novicios efectivo fue Juan Darío) (pero es un asesor constante de Torres. Incluso viaja en 1608 a España, volviendo en 1610 deja organizado el Colegio en Buenos Aires. Hacia 1614 es superior del Colegio de Chile y en 1619 está allí para fundar la vice-provincia de Chile). El padre Romero está un breve tiempo de visita como superior en Asunción, seguramente por el problema con los encomenderos. A partir de 1599 Romero reside en Córdoba. (en: Gracia, 2006, p. 67 y 84).

${ }^{19}$ Santiago del Estero, noviembre de 1585. El Padre Francisco Angulo "quedó de Superior de la Misión, ejerciendo también el cargo de Comisario en las tierras del Tucumán, con que le honró la Inquisición de Lima y durante los primeros años él y los otros, trabajaron fervorosamente en la ciudad, pasando más tarde a dar misiones por los cambios y rancherías" (Gracia, 2006, p. 39).

${ }^{20}$ Ya en 1591 el Padre Angulo había tomado posesión de una cuadra dada en Córdoba, que ocho años después será cambiada por la definitiva (Lozano, 1755).

${ }^{21}$ En 1593 el Padre Angulo sigue residiendo en Santiago del Estero. Al parecer, como es época de establecimiento entre las misiones, En 1597, mientras los otros jesuitas misionan en el territorio “...el P. Angulo, como comisario del Santo Tribunal, se ocupó en conservar la pureza de la fe, acudiendo donde le llamaba el cargo..." "el padre Angulo corrió misionando todo el río Salado, en la jurisdicción de Santiago del Estero..." (Gracia, 2006, p. 67 y 75).

${ }^{22}$ Un enemigo de Juan Ramirez de Velaszco en 1590 es fray Francisco Vázquez, dominico, administrador y vicario general del obispado, quien escribe al Rey desde Santiago del Estero, desmintiendo lo que pueda decirle el gobernador (Levillier, 1919, p. 493).
} 
Lima, donde los Inquisidores le dieron aquélla ciudad por cárcel, hasta que pidió su traslado a España y fue desterrado del Perú.

Tanto el padre Hernando Murillo, nombrado en tiempos del primer Cabildo eclesiástico del Tucumán por Victoria, actúa como agente "en comisión" para el padre Angulo en las cuestiones tocantes a despachos del Santo Oficio ${ }^{23}$. Resta decir, como ha sido harto estudiado, que los jesuitas mantuvieron con el obispo sucesor de Victoria, fray Trejo, excelentes relaciones ${ }^{24}$.

La creación de la Provincia Jesuítica del Paraguay, creada de manera legal 1604, y factual en $1607^{25}$ coincide con la llegada de su primer Provincial, el padre Diego de Torres $^{26}$ y el nombramiento como Comisario del Santo Oficio del Tucumán, y por tanto reemplazo de Francisco de Angulo en dicho ministerio, para un individuo muy influyente de la época en estas gobernaciones. Se trata de Francisco de Salcedo, sobrino y homónimo de aquél Salcedo que llegó a Santiago del Estero con órdenes del obispo Victoria en tiempos de Lerma y cuya prebenda eclesiástica había durado hasta su vuelta a España en 1588.

Francisco de Salcedo (sobrino), había llegado a Santiago del Estero en $1582^{27}$, donde fue nombrado Tesorero y deán de la Catedral con veintitrés años de edad. Protegido y apoderado del obispo Victoria, tras su salida de la diócesis queda como "administrador y gobernador" del obispado ${ }^{28}$.

El sucesor de Victoria, fray Fernando de Trejo y Sanabria, toma posesión del obispado en 1592 aunque alcanza Santiago del Estero recién en 1595. Tres años antes, desde España, había nombrado a Salcedo como Tesorero una vez más, así como vicario

\footnotetext{
${ }^{23}$ Francisco Angulo, sacerdote jesuita que misionó en la Gobernación del Tucumán en el siglo XVI. "En la ciudad de Córdoba a tres días del mes de Noviembre de 1595, ansí ante el padre Hernando Morillo clérigo presbítero, en virtud de una comisión que tiene despachada el Padre Francisco Angulo, Comisario de este Santo Oficio de la Inquisición de la Provincia del Tucumán..." (AHN MADRID; Iinquisición; 1647; exp. 3; Imagen Núm: 8/284).

${ }^{24}$ En el primer sínodo del Tucumán, de 1597 y realizado por Trejo, los jesuitas tuvieron una importante presencia. El padre Romero dio el sermón de apertura. "A él (sínodo) asistió el clero regular y el secular; predicó el Padre Juan Romero, Rector de la Compañía de Jesús, sobre indisciplina eclesiástica, los divinos misterios y la reformación de las costumbres, según lo dispone y manda el Pontificial. Fueron nombrados consultores del Obispo, por elección de éste, entre otros de diferentes órdenes y seculares, los Padres de la Compañía de Jesús, Francisco de Angulo, comisario del Santo Oficio, y Juan Romero..." (Gracia, 2006, p. 71).

${ }^{25}$ A comienzos del siglo XVII, había muy pocos jesuitas en la región.

${ }^{26}$ En 1609 Diego de Torres envía misiones al Guairá y en 1610 se fundan las reducciones de Loreto y San Ignacio (Maeder, 1996).

27 Información hecha de oficio por el Gobernador de las Provincias del Tucumán, Juan Ramírez de Velasco, de los clérigos y frailes de esa gobernación, de su calidad, antigüedad, méritos y servicios y experiencia de las cosas de la tierra. (Archivo de Indias; Santiago del Estero, 11 de noviembre de 1586. 74-4-1). Auto "del Gobernador, capitán general y justicia mayor en esta dicha gobernación e provincias de juríes e diaguitas e comechingones e de todo lo demás de la cordillera de Chile hasta el Río de la Plata". Pedido por el Rey, informa de la calidad y cantidad de personas eclesiásticas en la gobernación. Habla de Francisco de Salcedo, que ha llegado a la gobernación hacia 1581 y menciona a "los teatinos" Francisco de Angulo y Barzana: "son letrados y el uno predicador e predica a los naturales en la lengua e son de buena doctrina y ejemplo". Alrededor de cinco mercedarios (orden que ha llegado hace más de veinte años) franciscanos, alrededor de quince en cuatro conventos.

${ }^{28}$ En 1587 Victoria reemplaza a los tres del Cabildo y nombra, entre ellos, a Francisco de Salcedo (sobrino del anterior) en el cargo de tesorero (Tedesco y Crouzeilles, 2005, p. 37).
} 
general y provisor ${ }^{29}$ de la diócesis del Tucumán por pedido expreso a Felipe II, en tanto gobernador interino de la 'sede vacancia' del obispado (Cabrera, 1934; Càrcano, 1929).

De los vínculos entre la Compañía de Jesús y el Tesorero Francisco de Salcedo, ha quedado sobrada evidencia. Como aquél conocido acontecimiento que encontró a Salcedo junto a los primeros jesuitas de la Asistencia de Portugal que arribaron al territorio rioplatense vía Atlántico. Sucedió en 1585, cuando una fragata que volvía del Brasil y en la que viajaban misioneros de la Compañía de Jesús y el licenciado Salcedo, con correspondencia y documentos para el obispo Victoria, fue tomada prisionera por navíos ingleses en las costas del Plata ${ }^{30}$. Asimismo, cuando Trejo y los jesuitas comienzan con aquel largo y accidentado proyecto de establecimiento de un Colegio Máximo, ya como obispo de Santiago de Chile, Salcedo los apoyará, legando en su testamento todos sus bienes para esta futura institución ${ }^{31}$. No son menos significativos los pedidos de Diego de Torres al Rey para que nombrase a Salcedo como obispo en reemplazo de Trejo, tras su muerte a fines de $1614^{32}$.

\footnotetext{
${ }^{29}$ El Provisor General y Vicario General, al igual que el Obispo, tienen poder de justicia criminal atinente a la persecución de 'herejías', como el poder que da Trejo a Miguel de Milla en 1599: “... proveer en lo que fuere necesario, inquirir y proceder contra sacrílegos y otros cualesquiera delincuentes y acusados del crimen de herejía, que nos como ordinarios podemos y debemos castigar, haciendo en todo lo que
} fuere justicia" (Palomeque, 2005, p. 107).

${ }^{30}$ En aquél célebre viaje de 10/1585 de los jesuitas desde Buenos Aires a Salvador de Bahía, en una fragata (que costó 4000 pesos), y en donde llevaban cartas para el Padre Provincial de Bahía, iba el Licenciado don Francisco de Salcedo. Volviendo del mismo viaje unos piratas ingleses toman prisioneros a todos los integrantes de la misión. De acuerdo a Gracia, una Relación de la época dice: "quedáronse... en el navío mayor el P. Francisco Salcedo con los PP. De la Compañía; y 18 días después que les dejaron los ingleses, entraron por la boca del Río de la Plata y llegaron a la ciudad de Buenos Aires, todos desnudos, así los PP. Como los demás, sin traer más que las camisas rotas...." (Gracia, 2003, p. 41). Levillier recuerda el hecho de esta manera: "Diario del viaje y arribada a Buenos Aires de los religiosos de la Compañía de Jesús y portugueses procedentes del Brasil, llamados por el Obispo de Tucumán, D. Francisco de Vitoria, y relato de lo ocurrido con unos corsarios ingleses (año 1587, 74-4-1) 'a 20 de enero día de San Sebastián que llegamos a la boca del río que tiene 30 leguas de ancho y al nacer del día dimos en la misma boca con tres navíos ingleses que estaban mar a través para entrar dentro para tomar agua, para hacer su viaje y como era tiempo bonacible y estábamos tan cerca de ellos aunque los dos navíos que traíamos eran muy buenos de la vela no pudimos huir y con sus bateles y la lancha que tría remos vinieron a bordo de nuestros navíos de todo cuanto traíamos sin dejar en ellos más que un poco de arroz podrido y un poco de harina de mandioca, trajeron nos consigo 28 días y nos llevaron a altura de 43 grados camino del estrecho de Magallanes, hasta donde nos llevaron presos y los navíos consigo haciendo muchas consultas cada día sobre si nos matarían y estuvieron determinados de matar al padre Leonardo de Armiño y sus compañeros y al padre Francisco de Salcedo criado del Reverendísimo de Tucumán" (Levillier, 1919, pp. 399-408).

${ }^{31}$ Fue consagrado como Obispo de Santiago de Chile en 1624 (en Charcas, y viajóal año siguiente a Chile). Fallece en 1635. En 1613 Salcedo es trasladado a la Catedral de Charcas, donde figura como canónigo. Y luego también Deán (deja 'fundado' un colegio de jesuitas en San Miguel de Tucumán, en virtud de un permiso dado por Viteleschi, el General de la Compañía de Jesús (Avella Chafer, 1944).

${ }^{32}$ Es interesante el modo en que, en Acta del 22 de enero de 1595, se describe la toma del poder como Provisor Salcedo: “...y continuando la dicha posesión, la recibía y aprendía. Y en señal de ella se paseó por el dicho coro y abrió un libro de canto y entonó una antífona, hallándose a todo presente con el dicho deán y cabildo el señor don Pedro de Marcado Peñaloza, gobernador de estas provincias. (Salcedo tiene al parecer aptitudes para la música, con el pedido de músicos en 1592, este canto y luego en 1596 pide aderezar el órgano de la Catedral. Tenía Salcedo también dinero propio, estancias y una renta de los diezmos en beneficio de su prebenda que le permitió costear la construcción de la catedral de Santiago, viajar por el Perú y fundar (es decir, dotar económicamente) colegios de jesuitas en el Tucumán. Como han afirmado Tedesco y Crouzeilles: “...las dignidades ocupaban la categoría más alta y tenían derecho al 
Como apuntamos más arriba, Salcedo fue designado como Comisario del Santo Oficio para el Tucumán en $1605^{33}$, y aunque fueron sólo seis años los que estuvo a cargo de la justicia inquisitorial en la diócesis, bajo su comisariato se organizan, como se verá, los distritos inquisitoriales correspondientes a las ciudades de Buenos Aires, Paraguay, Córdoba y Santiago del Estero.

Salcedo es enviado en 1613 a La Plata, donde intenta conseguir sin éxito la prelatura del Tucumán como canónigo, sin embargo, apoya desde el nuevo Arzobispado de Charcas del que la diócesis tucumana se convierte en sufragáneo ${ }^{34}$. Desde allí, trabaja activamente por el nombramiento de cargos y prebendas eclesiásticas para hombres de su confianza y que habrán de ocupar también luego cargos en el Santo Oficio. Uno de ellos fue el Doctor don Fernando Francisco de Rivadeneyra, para quien Salcedo consigue en 1611 la prebenda de Maestrescuela, y de Chantre de la Catedral de Santiago del Estero para 1615, con Real Cédula de Felipe III. Por estos años Rivadeneyra consigue el cargo de Comisario del Santo Oficio de Santiago del Estero; del mismo modo que el sacerdote Diego de Trejo lo hace para Buenos Aires, también a través de las gestiones de Salcedo ${ }^{35}$.

El último de estos nombramientos organizados por Salcedo desde Charcas, se refiere al del Licenciado Antonio Rosillo en 1616. Salcedo y Rosillo se conocieron presumiblemente en Córdoba ${ }^{36}$ y coincidieron en Charcas en los años en que Salcedo ofició allí de canónigo. Vinculado, al igual que Salcedo, de manera estrecha con la Compañía de Jesús, Rosillo habrá de marcar el primer medio siglo de la justicia inquisitorial en Córdoba (Sartori, 2015).

\section{Causas inquisitoriales del antiguo Tucumán}

Tras la instauración del Tribunal del Santo Oficio limeño en 1570, recién los 'brazos' de la Inquisición alcanzaron la vasta gobernación del Tucumán en 1585, con el nombramiento del jesuita Francisco de Angulo, a instancias del obispo Victoria. La designación de Angulo como Comisario del Tucumán ${ }^{37}$ duró hasta 1607, y fue reemplazado por el clérigo, deán y luego también tesorero de la Catedral de Santiago del Estero; quien ejerció el cargo hasta 1613, cuando nombra en su lugar a varios

\footnotetext{
título honorífico de don más el título adicional de su cargo: deán, arcediano, chantre, maestrescuela y tesorero.” (Tedesco y Crouzeilles, 2005, p. 29).

33 “... siendo más tarde designado comisario del Santo Oficio y de la Santa Cruzada...” (Palomeque, 2005, p. 190). También mencionado con este cargo en: Levillier, 1926, pp. 77 y 99).

${ }^{34}$ Francisco de Salcedo firma sesenta y seis Actas (de alrededor de dos por año) desde 1592 hasta 1617 de manera casi ininterrumpida. Pero los últimos años no era ya como cabildante del Tucumán, sino de Charcas (Palomeque, 2005, 79-190).

35 En 1616 muere Milla y “...ha quedado dicha iglesia y obispado del Tucumán sin jurisdicción eclesiástica..." (Palomeque, 2005, p. 177). Ese mismo año le responden de La Plata, y uno de los que firma es Francisco de Salcedo. (junto a Diego de Trejo, quien será luego comisario en Buenos Aires), y le dicen al cabildo acate eso mismo que ellos han dispuesto. (Palomeque, 2005, pp. 176 y 181).

${ }^{36}$ En 1602 Salcedo vivía en Córdoba, en el solar designado para Hospital (En 1602 Salcedo vivía en una edificación cercana a la Plaza Mayor en Córdoba, que servía también al hospital de Santa Eulalia (Archivo Municipal, p. 106).

${ }^{37}$ Ambos comisarios son nombrados en los documentos como 'Comisarios del Tucumán', es decir que su jurisdicción hacía referencia a la propia del obispado homónimo.
} 
comisarios para las distintas ciudades del Tucumán, dividiendo así la jurisdicción y ampliando el control impuesto por la Inquisición a este territorio.

Es decir que, estos primeros dos comisarios, Angulo y Salcedo, tuvieron a su cargo una jurisdicción inmensa, que abarcaba en teoría la diócesis del Tucumán, pero que en la práctica se extendió también hacia todo el Río de la Plata y el Paraguay ${ }^{38}$.

Durante veintidós años Angulo y Salcedo ejercieron de comisarios avalados por el Tribunal de la sede virreinal, y asistidos con armas y dinero por las autoridades civiles locales de cada ciudad del Tucumán. Francisco de Angulo, como era habitual entre los jesuitas, viajaba constantemente, por lo que las causas durante su ministerio provienen de todas las ciudades de la región, incluyendo Asunción y Buenos Aires ${ }^{39}$. Mientras que, por su parte, Francisco de Salcedo, que residía durante la mayor parte del tiempo en Córdoba, ejerció su cargo de modo más localista, limitándose a Córdoba y Santiago del Estero.

La mayoría de las causas no prosperaron, pero sirvieron a los comisarios para neutralizar a los acusados, trasladándolos presos a Lima y algunas veces encerrados en las cárceles del Santo Oficio durante años. Del período que abarca ambos comisariatos, lamentablemente se conservan pocos datos. Como hemos señalado en el capítulo sobre fuentes relativas a las causas judiciales de la Inquisición peruana, la mayoría de los procesos de fe realizados en el Tribunal de Lima han desaparecideo, y solo quedan algunos casos dispersos que habían sido enviados en copia al Consejo de la Suprema, junto a aquellos listados de 'relación', algo así como un resumen de cada causa, pendiente o con sentencia ${ }^{40}$.

Sobre la base de esta documentación, hemos podido identificar, para la época de Angulo y Salcedo, cincuenta causas contra individuos residentes en las gobernaciones del Tucumán, Paraguay, Río de la Plata. De las cuales veintidós corresponden al delito de solicitación, ocho al de bigamia, siete al de blasfemia y proposiciones heréticas, tres contra portugueses judaizantes, y solo uno de brujería, otro de luteranismo y un delito propio del clero. Las causas referidas al Obispo Victoria, a Lerma y a otras autoridades gubernamentales dependientes de ellos en el Tucumán han sido tratadas en apartado anterior, pero volveremos sobre ellas más adelante.

Estos números nos dan un promedio de dos causas por año y casi la mitad referidas a la persecución de frailes y clérigos solicitantes en el Tucumán; seguidas por la bigamia y la blasfemia, de una causa cada dos o tres años; y finalmente una presencia solo casual de brujería y luteranismo, resabio lejano de la Inquisición fogoneada por el emperador Carlos V para toda Europa en la primera mitad del siglo XVI. Las tres causas contra judaísmo corresponden al comisariato de Salcedo. Junto a ellas, las acusaciones sobre prácticas judaicas levantadas contra Victoria, así como la condena de hermano por el mismo delito, serán los primeros antecedentes de una persecución a conversos en el Perú, que comienza a acelerarse a partir del coronamiento de Felipe II como rey de

\footnotetext{
${ }^{38}$ Es posible, aunque no está comprobado, que en Paraguay actuase el jesuita llamado fray Martín Ignacio de Loyola desde 1597.

${ }^{39}$ La región de Cuyo tuvo también una importante actuación inquisitorial, que fue ejercido desde Chile en en una red de comisarios y ministros inquisitoriales de forma independiente a lo sucedido en Tucumán, Río de la Plata y Paraguay, aunque ciertamente con vínculos y contactos permanentes. Algunos de estos individuos aparecen en la burocracia inquisitorial cordobesa, sobre todo desde mediados del siglo XVII. Estas vinculaciones aparecen desarrolladas en los capítulos integrantes de la parte V.
}

${ }^{40}$ AHN CHILE; Inquisición; Fondo Simancas; Volumen 23; Procesos s. XVI. 
Portugal, como consecuencia del incremento de migrantes luso-brasileros al territorio virreinal surperuano.

\section{La carta de Diego de Torres a la Inquisición de Lima, o los discursos del poder}

El sacerdote jesuita Diego de Torres, fue uno de los principales artífices de la empresa evangelizadora -imperial y católica- en las lejanas gobernaciones pertenecientes al Perú ${ }^{41}$. Fue el primer Provincial de la Provincia jesuítica del Paraguay, que comprendía en imprecisos límites los actuales territorios de Paraguay, Argentina, Uruguay, sur de Brasil y de Bolivia, y Chile.

Tras recorrer todo el territorio, el padre Torres estableció la sede de la nueva Provincia en la ciudad de Córdoba del Tucumán, punto neurálgico de comunicaciones para todo el vasto espacio que abarcaba la jurisdicción provincial jesuítica. En Córdoba, hacia 1610, establece el Colegio Máximo y comienza una intensa labor de financiación para esta institución que podrá otorgar grados universitarios en 1622 (Piana y Sartori, 2012), al tiempo la orden va adquiriendo estancias agrícola-ganaderas, esclavos y rentas en todas las gobernaciones de la región, fundando además las primeras misiones o reducciones de indios en la región del Guairá donde con anterioridad los jesuitas del Brasil habían creado las residencias de Asunción y Villarrica y dos reducciones en las afueras de esta última. Del mismo modo que las encomiendas cordobesas ${ }^{42}$ y chilenas ${ }^{43}$, uno de los principales problemas a los que se enfrenta la Compañía en esta época es precisamente en aquélla inmensa selva paraguaya.

Allí, pocas ciudades españolas sobreviven, aun cuando la alta densidad demográfica de los tupí-guaraní los convierte en un recurso humano codiciado por españoles encomenderos. Del mismo modo, también están interesados en esas poblaciones indígenas no insertas aun en el sistema colonial, aquellos colonos portugueses, armados como ejércitos privados, quienes bajaban en incursiones de razia

\footnotetext{
${ }^{41}$ En el resto del Perú, la actividad de los jesuitas fue intensa y se orientó no sólo a la evangelización sino también a la extirpación de idolatrías en: (Ramos y Urbano, p. 153). Allí se exponen además los argumentos teológicos y filosóficos que soportaron el andamiaje sobre el cual la Orden incorporó el catolicismo en gran parte de América.

${ }^{42}$ En Córdoba, aunque no de manera exclusiva, los jesuitas se involucran en la cuestión de las encomiendas y el maltrato de los indios en la región. Logran llevar a la región al oidor Francisco de Alfaro, quien redacta las famosas Ordenanzas, además de iniciar activamente juicios contra los abusos de los encomenderos: ej. AHPC; Esc. 1; Años 1611; Leg. 23; Exp. 8. Esta intervención les significará a la Orden una resistencia de los vecinos de Córdoba, que los obligará a marcharse durante un año de la ciudad.

${ }^{43}$ Aunque Torres es consciente de que sobre esto el Tribunal no tiene jurisdicción alguna, igual lo comenta. "Todo lo cual entiendo ha permitido Dios Nuestro Señor en estas gobernaciones y los demás males en la de Chile por el servicio personal que en ellos se ha conservado contra todo derecho y cédulas reales que ha sido causa de que se hayan consumido los indios y haya tantos infieles y los cristianos vivan como si no lo fuesen y se huyan, pero que los españoles hayan vivido en mal estado como también sus gobernadores y confesores que por ventura tienen la principal culpa y mientras esta raiz de todos estos males y de el de las malocas, no las quitaren los ministros de su Majestad, a cuyo cargo ésta dudo que los demás indios surtan y tengan efecto y no digo a vuestra Señoría los gravísimos males que han resultado de una maloca que de esta se hizo para traer indios al servicio personal porque veo no pertenece a el remedio a ese Santo Tribunal, si bien lo podía tocar por no ser el medio más cierto con que el demonio impide la conversión de la gentilidad y que con ella desacredita totalmente Nuestra Santa Fe y ley evangélica". Biblioteca Nacional de Chile. Fondo José Toribio Medina (1852-1930) 8071. Reglas establecidas por el jesuita Diego de Torres sobre el servicio personal de los indios de Chile. 1609.
} 
para capturar indios, para llevarlos a São Paulo con el fin de venderlos como esclavos (Maeder, 1996).

Evidencia de esta situación de conflicto, es una carta escrita en Córdoba del Tucumán por el padre Diego de Torres el 24 de septiembre de 1610 y dirigida a los Inquisidores del Tribunal del Santo Oficio de Lima ${ }^{44}$. Recibida en el Tribunal en febrero del año siguiente, esta carta tuvo un efecto crucial para el nombramiento de un mayor número de ministros y, consecuentemente, un mayor control de la Inquisición en el Tucumán el Río de la Plata, Paraguay y Chile ${ }^{45}$. La carta presenta, sin embargo, un doble discurso a los fines de conseguir una intención distinta a la proclamada ${ }^{46}$.

Luego de las formalidades de rigor entre altas autoridades de la Iglesia en el Virreinato $^{47}$, Diego de Torres les dice que escribe para informarles sobre lo que ha observado "estas tres Gobernaciones" que ha recorrido él mismo. Y que en ellas había "grandes riesgos" y "(pocas raíces) en el divino acatamiento que la fe de los españoles".

La razón que encuentra para afirmar esto es, según escribe,

"la larga noticia de que por el puerto de Buenos Aires, y por San Pablo y la Asunción entra gente inficionada de judaísmo y de nación portuguesa tan bien se debe velar y cuidad no pasen otras naciones inficionadas con herejías, el Gobernador pasado (Hernandarias), con su gran experiencia y celo hizo gran esfuerzo para remediar esto, y al presente -que es muy fiel ministro- hace cuanto puede, y no ha habido remedio." 48

\footnotetext{
${ }^{44}$ Consultamos el original de este documento, en: AHN MADRID; Inquisición; libro 353, fol, 42. Así como la copia realizada en el siglo XIX por el equipo de paleógrafos dirigidos por Medina ya mencionados anteriormente. Este documento se encuentra en: AHN CHILE; Inquisición; Fondo Simancas; Libro 760.60. Pieza 37. En el libro referido, folio 92 noventa y dos se halla la copia lo siguiente: "Copia de carta del Padre Diego de Torres Provincial de la Compañía de Jesús en las Provincias de Chile, Tucumán y Paraguay escrita al Santo Oficio de la Inquisición del Perú, recibida el 17 de Febrero de 1611, que es del tenor siguiente: (al margen der: sobre escrito IHS)".

${ }^{45}$ Un tema secundario en la carta es la cuestión tratada por Torres sobre la "maldita yerba", planta de infusión frente a cuyo consumo se opone la Orden en estos años, que no es otra que la "ilex paraguanensis", o yerba mate, luego producida de manera extensiva por los jesuitas en las misiones guaraníticas.

46 Tanto Aspell (p. 70), como antes Medina (p.154), Lewin (p. 130) y Castañeda Delgado/Hernández Aparicio (Tomo I, p. 53) sostienen que esta carta de Diego de Torres era en contra de los judíos y su abundante presencia en el Río de la Plata, Tucumán, Chile y Paraguay. Nosotros sostenemos que, en realidad, el intento por controlar a los portugueses en la región mesopotámica del Plata no se debía al origen religioso de los mismos, sino más bien por el común interés que tenían jesuitas y lusitanos paulistas sobre los indios. Los primeros para evangelizarlos y 'reducirlos' en Misiones, los segundos para esclavizarlos.

47 “A los muy Ilustres Señores Inquisidores Apostólicos de estos Reinos y Provincias del Perú. Mis muy señores de Lima. Muy Ilustres Señores.”

${ }^{48}$ Junto a los portugueses supuestamente herejes, Torres incluye a otros individuos, con perfil de criminales "Otra causa y raíz de esta poca fe es que no sólo ha entrado por Buenos Aires y San Pablo alguna gente portuguesa que se ha avecindado nueva en ella entre la mucha que hay, pero como desde el principio se ha poblado estas dos Gobernaciones de alguna gente que forajida, y perdida del Perú y ha habido pocos hombres doctos y de buenas costumbres, están estas muy estragadas y cada día serán peores."
} 
Al parecer los jesuitas habían avisado de esto al Rey, en cuya Corte solo se había respondido con el nombramiento de un nuevo Gobernador del Paraguay ${ }^{49}$, quien tenía intención de "bajar" la Catedral del Obispado desde Asunción ${ }^{50}$ al puerto de Buenos Aires para que el obispo actuase allí como "inquisidor ordinario" contra los conversos contrabandistas; algo que alarmaba a la Compañía pues suponía dejar sin poder eclesiástico a la región fronteriza con el Brasil,

"Remediará mal el daño que viene por tierra desde San Pablo los inconvenientes que este medio parece que tenía, son primero dejar desamparado todo el Obispado, segundo no lo poder visitar el Obispo..."51

Es decir que con ello dejaban a todo el Paraguay abierto al ingreso de las bandeiras paulistas y del abuso de los encomenderos de Asunción. Asimismo, juntaban en un mismo lugar, el contrabando y un prelado de diócesis sin control: "...por que si acaso el Obispo diese en codicioso como no tiene acá superior podría hacer más daño que provecho.",52

Torres conoce a los Inquisidores y sabe cuánto les molesta el ejercicio de la inquisición ordinaria por parte de los Obispos, en una jurisdicción que consta de Tribunal. Y es por eso que toca allí, al reflexionar que,

"parece que al Tribunal Santo de la Inquisición lo podría ser esto molesto, y causa de encuentros tomando los Obispos por ventura más mano de la que convendría, y lo cuarto tener mal remedio los agravios que hiciese y molestias que diese al gobernador y Oficiales Reales." 53

Frente a todos estos conflictos, fundamentalmente a la cuestión del ingreso de "herejes", el padre Torres propone una única solución, basada en las "acordadas" que había firmado el Tribunal con el Virrey del Perú: nombrar comisarios inquisitoriales para Asunción, Córdoba y Santiago de Chile, dividiendo así la gran Comisaría del Tucumán que fue ejercida por el jesuita Angulo y luego por el deán Salcedo hasta 1613. Algo que se visibiliza en la carta es que para estos años, Buenos Aires ya tenía comisario. Sobre Asunción dice,

"es muy conveniente que en la Asunción haya comisario porque el de Buenos Aires no puede subir por allí y lo segundo porque todos los que entran por San Pablo llegan allí y no les faltan medios para escaparse y no basta comisión del comisario de Buenos Aires como ahora lo tiene el Padre Diego González, hermano del Señor Inquisidor Becerra, porque es para cosas particulares, y no puede remediarlas muchas se ofrecen en todo aquel distrito que es 400 leguas",54

\footnotetext{
${ }^{49} \mathrm{Su}$ Majestad le ha consultado, para poner otro que demás de no ser eficaz -a mi pobre juicio- tiene graves inconvenientes (Diego Martín de Negrón (1609-1613),

${ }^{50}$ Tal como desea la Compañía, se divide el Obispado del Paraguay, creándose el del Río de la Plata en 1620. Aunque esto no acabó con los conflictos jurisdiccionales, sino que, bajo la administración de algunos obispos (como Cárdenas), se volvió aún peor.

${ }^{51}$ Ibidem

$522^{\circ}$. Si no tuviese entereza y le dejase llevar de intercesiones o frase alguna cosas de callados no sería este medio de provecho, la $3^{\circ}$. Por lo menos en sede vacante no lo sería (sede vacante por muerte de Reginaldo de Lizárraga, O.P. (10 de noviembre de 1609).

${ }^{53}$ Ibidem.

${ }^{54}$ Ibid.
}

17 Federico Sartori Moyano. Los jesuitas y la Inquisición al sur del Perú... 4-26. 
Es decir que con este comisario, más el Obispo con la sede también en Asunción, se proponía un control de 'justicia penal' a los portugueses. De Córdoba argumenta que,

"es muy necesario que viviera aquí en Córdoba otro comisario porque los que se escapan de Buenos Aires vienen todos aquí y se pueden ir al Perú sin tocar en Santiago y cuando hubiese de haber un solo comisario antes debía estar aquí que no allí porque todos los que van y vienen del puerto tocan allí o ser como el Padre Angulo que desembarcado de haciendas y dignidad y oficios estuviese aquí cuando va y viene la gente y lo demás del año visitase disimuladamente pasando en su religión." 55

La cuestión en Chile es harto más compleja, pues se encuentra por estos años en pie de guerra, entre araucanos y españoles. De tal modo que la presencia de la Iglesia es aún menor y de la Inquisición, inexistente.

"En lo que toca a la Gobernación de Chile sólo añado que entendí había necesidad de que el comisario o alguna persona pasara de satisfacción fuese más como confesor que como ministro a visitar los fuertes porque muchos soldados que están años allá en ellos tienen gravísimas necesidades y si no se remedian serán cada día mayores y de mayores inconvenientes."

Torres se toma la libertad de opinar acerca de lo que estos nuevos comisarios debían hacer, sobre todo en lo que respecta a los portugueses: Como no permitirles desembarcar "so graves penas" y que solo lo hiciese quien "trajese licencia de $\mathrm{Su}$ Majestad y del Santo Oficio de la parte donde viniese", del mismo modo que, embarcándose para salir por el puerto, ningún portugués lo hiciera sin estar antes examinando con licencia de la Real Audiencia y del comisario de su distrito. Además, recomendaba que el se diese orden al comisario de Buenos Aires, de "visitar" todos los navíos junto a su juez y alguacil mayor

La influencia de Torres es, al parecer, muy alta en las cortes Virreinales y los Inquisidores hacen caso de su petición. Una vez que su misiva ingresa al Tribunal, es leída y archivada en la Cámara del Secreto. Y en abril de ese mismo año se escribe un auto con la orden siguiente:

"habiendo visto la carta que el Padre Diego de Torres Provincial de la Compañía de Jesús en las provincias de Chile, Tucumán y Paraguay, su pareciere (sic) conviene haya Comisario en Córdoba de ese Santo Oficio, lo proveeréis en persona cual convenga y en lo demás que (...) en la dicha carta haréis justicia en lo que os tocare por razón de vuestro oficio sin entrometeros en otra cosa."

Como consecuencia de esta gestión, es nombrado en 1614 como comisario Inquisitorial para todo el Paraguay el sacerdote jesuita Marciel de Lorenzana, en reeemplazo de otro miembro de la Compañía de Jesús, el Padre Diego González Holguin, quien había comenzado a ejercer el ministerio inquisitorial por primera vez en

\footnotetext{
55 Ibid.

${ }^{56}$ Ibid.

${ }^{57}$ AHN MADRID; Inquisición; Leg.353; f42v-78v. Luego la carta habla de los conflictos de que se queja el sto. Of. limeño con los virreyes, audiencias -y sus fiscales y oficiales-, y de cómo el Rey ha apoyado esa situación, y que se seguirá intentando que éste permita a los oficiales del Tribunal limeño viajen con esclavos y armas hacia el Perú.
} 
1607 (Page, 2017, pp. 167-171). Otros comisarios son nombrados también al poco tiempo, como el Licenciado Antonio Rosillo, sacerdote secular profundamente vinculado a los jesuitas y Fray Fernando Franco de Ridaeneyra, el primero para Córdoba y el sgundo para Santiago del Estero. Como vimos, ambos comisarios fueron nombrados a instancias de otro hombre vinculado a la Compañía, el Deán Francisco de Salcedo, sugundo comisario inquisitorial en la Gobernación del Tucumán.

Pero hay algo más al respecto de la carta de Torres que vale la pena remarcar. Y esto es que su presión para que se nombrasen comisarios inquisitoriales no solo habría de tener como resultado un escaso control de los ataques bandeirantes a las misiones, sino también una cada vez mayor persecución a conversos portugueses que nada tenían que ver con los tratantes de esclavos paulistas.

Y además, si bien es cierto que todos los bandeirantes eran portugueses, no todos los portugueses eran conversos. Torres parece haber sido consciente de estas disquisiciones al respecto del perfil de individuos que habrían de ser reprimidos y no en utilizar la 'herejía' como elemento disuasivo para sumar controles a la cuestión en las misiones, así como en la protección de los indios encomendados en el interior del Tucumán y Chile. Dicho de otro modo, que aún cuando en realidad la persecución impulsada por los jesuitas contra estos portugueses no era racial ni religiosa, la antigua persecución de la Inquisición y del Imperio a los conversos les sirvió como excusa y arma de lucha geopolítica y de dominio sobre las poblaciones indígenas de la región. Sin proponérselo, la Compañía de Jesús acabó por crear un nuevo conflicto, esta vez interno, asentado sobre la persecución a hombres y mujeres acusados de conversos, aun cuando el estrecho vínculo de la orden con los comisarios nombrados generase durante el siglo XVII una menor presión de la justicia del Santo Oficio sobre estas regiones periféricas que el ejercido en los distritos cercanos al Tribunal limeño.

En realidad, los jesuitas tuvieron durante toda su historia una percepción, al respecto de los 'cristianos nuevos' y de las 'probanzas de limpieza de sangre', alejada de los preceptos religiosos de la Inquisición moderna española. Pues, como sostuvo Bataillon en su libro sobre los jesuitas españoles del siglo XVI (2014), la Compañía de Jesús no diferenciaba a cristianos 'viejos' de 'nuevos', basándose en el principio religioso de que si nada menos que Jesús y la Virgen María habían sido judíos, nadie podía ser perseguido por serlo. Sosteniendo además que el catolicismo era una religión fundamentalmente de 'conversión', de tal manera que era su deber evangelizar y atraer a la fe a toda la humanidad, sin juzgarlos ni perseguirlos por no haber sido aún atraídos a la fe católica. Quizás la prueba más fehaciente de ello sea que desde la fundación de la Orden, hubo incontables jesuitas cuya condición de 'cristianos nuevos' no fue impedimento para acceder a la más alta jerarquía de la Orden.

Esta característica de la Compañía de Jesús fue exhibida en acciones concretas que se remontan a los primeros tiempos de la Orden y a los preceptos de Ignacio de Loyola. Incluso el sucesor de éste, como General de la Orden, Diego Laínez, provenía, de acuerdo a Bataillon, de una familia de "mercaderes cristianos nuevos de Amazán" (Escudero, 2005, p. 41).

Desde un punto de vista político y económico, los jesuitas entendían que en América, la restricción a este amplio grupo social actuaba en menoscabo de sus intereses de expansión evangelizadora, ya que eran los mercaderes lusitanos quienes manejaban en gran medida el comercio interregional a escala virreinal y aun ultramarino, dentro de toda la amplia región que abarcaba la Provincia Jesuítica del 
Paraguay. Y más allá, hasta las costas del Brasil y del África esclavista, con conexiones en toda Europa y gran parte de sus colonias. Eran conscientes de que el camino para la concreción de su proyecto educativo y de evangelización tridentina, cuya necesidad económica dependía en gran medida de dicha estructura comercial, era asociarse a ellos, no perseguirlos. Para la Orden, no era condición de excepción que un individuo fuese cristiano 'viejo' o 'nuevo', siempre y cuando su fe fuese sincera.

Para el caso del amplio territorio tucumano durante el siglo XVI, puede observarse que los jesuitas han estado, desde la época inmediatamente posterior a la conquista, involucrándose en la justicia inquisitorial, a los fines de establecer un efectivo y propio control del territorio, utilizando la criminalización de la fe con fines geopolíticos y sobre la base de una filosofía evangélica Contrarreformista. Después de Aguirre y los demás conquistadores tardíos del Tucumán, en que órdenes religiosas y el clero secular se unen en muchos casos para contrarrestar el poder de los encomenderos $\mathrm{y}$ funcionarios de gobierno.

Como un modo de equilibrar la dominación de particulares sobre territorio imperial, la Corona se esforzó en avanzar sobre el territorio también con la Iglesia. Primero con los franciscanos (fray Juan de Rivadeneyra, comisario general de San Francisco en el Perú) y luego, al no prosperar, impulsando la llegada de jesuitas. Poco a poco, los jesuitas van llegando a la región, para tomar residencia en las principales ciudades del Tucumán, realizando misiones volantes a tierras cada vez más lejanas, hasta alcanzar la selva de los tupí-guaraní, al noreste del inmenso Paraguay. El problema en estos años es, principalmente, el abuso de frailes y curas con los indios, algo que la Compañía intenta remediar con el fuero inquisitorial, que sustenta.

Luego, cuando sucede la unión de Portugal a la jurisdicción de Felipe II en 1580, y se abre esta región hacia la boca atlántica luso-española que permitió el paulatino ingreso de portugueses presuntamente conversos al Virreinato del Perú, los jesuitas intentan controlarlo una vez más con el poder de la Inquisición de Lima. Sin embargo, habrán de pasar más de tres décadas hasta que en 1613 su presencia, manifestada en la figura de comisarios residentes en las más distantes ciudades del virreinato, muestre una aplicación de la justicia inquisitorial en las regiones más periféricas del Imperio y, con ello la malla inquisitorial ${ }^{58}$ del Imperio español, finalmente, se cierre.

\section{Palabras finales: Jesuitas comisarios o la dominación del territorio}

Luego de las gestiones del padre Diego de Torres, la influencia de la Compañía de Jesús en la región sería tan intensa que intervendría incluso en la acción judicial inquisitorial del territorio. Y precisamente es en este contexto en el que aparecen numerosos mercaderes portugueses de origen converso, que formaban parte de esta compleja maquinaria financiera, económica y comercial que caracterizó a estos territorios durante el siglo XVII, lo que explicaría el esfuerzo inquisitorial en controlar toda esta amplia jurisdicción, con el fin de perseguirlos y secuestrar sus bienes. Pues el grupo más perseguido y perjudicado de esta época fue el conformado por los conversos portugueses residentes en el Perú ${ }^{59}$.

\footnotetext{
58 “sobre aquél mundo político español (americano) de la monarquía universal se había cerrado, al fin, la malla inquisitorial” (Escudero, 2005, p. 24).

${ }^{59}$ Bien distinta fue la situación de los cristianos nuevos en Portugal. Del mismo modo, la relación entre la Inquisición portuguesa y la Compañía de Jesús en territorio lusitano tuvo características propias y
} 
Se ha demostrado que durante poco más del primer siglo de existencia del Tribunal de Santo Oficio limeño, que tuvo la mirada puesta en los 'cristianos nuevos'. Hombres y mujeres, conocidos y en muchos casos juzgados como 'conversos' 'marranos' o 'cristianos nuevos', con ascendencia judía de padres o abuelos condenados o reconciliados por la Inquisición, quienes ante una delación podían ser acusados de falsa conversión al catolicismo y sentenciados a muerte; importando más el origen genealógico que la fe, y en más de una ocasión con el verdadero objetivo de enriquecer al Santo Oficio y a sus miembros a costa de la fortuna de aquellos.

Parte fundamental en la construcción del Imperio español, sin embargo, los jesuitas tenían, al respecto de los conversos, ideas distintas a las de la Corona. En su libro sobre los jesuitas españoles del siglo XVI, Marcel Bataillon ha estudiado en profundidad la aceptación de los jesuitas al respecto de los conversos. Actitud ésta que, claramente contraria a los preceptos político-religiosos fundamentales de la Monarquía española moderna, se remontan a los primeros tiempos de la Compañía y a los preceptos de Ignacio de Loyola. Porque en el contexto de la fundación de la orden, los jesuitas estaban más inclinados a no diferenciar cristianos 'viejos' de 'nuevos', basándose en el principio religioso de que si nada menos que Jesús y la Virgen María habían sido judíos, nadie podía ser perseguido por serlo. Sosteniendo además que el catolicismo era una religión fundamentalmente de 'conversión', de tal manera que era su deber evangelizar y atraer a la fe a toda la humanidad, sin juzgarlos ni perseguirlos por no haber sido aún atraídos a la fe católica. Quizás la prueba más fehaciente de ello sea que desde la fundación de la Orden, hubo incontables jesuitas cuya condición de 'cristianos nuevos' no fue impedimento para acceder a la más alta jerarquía de la Orden.

Desde un punto de vista político y económico, los jesuitas entendían que en América la restricción a este amplio grupo social sólo actuaba en menoscabo de sus intereses de expansión evangelizadora; ya que eran los mercaderes lusitanos de origen judío quienes manejaban en gran medida el comercio interregional a escala virreinal y aun ultramarino, dentro de toda la amplia región que abarcaba la Provincia Jesuítica de la Paraquaria; y más allá, hasta las costas del Brasil y del África esclavista, con conexiones en todo Europa y gran parte de sus colonias. Conscientes, de esta manera, que el camino para la concreción de su proyecto educativo, basado necesariamente en una fuerte estructura económica, era asociarse a ellos, no perseguirlos. De tal manera que también con el fin de no permitir que desapareciesen sus vínculos con miembros fundamentales de la estructura del comercio surperuano, y gracias al lugar de periferia de estos territorios frente al poder inquisitorial central, la Orden los protegió. Y ello a través del capital relacional que lograron establecer con los ministros locales del Santo Oficio, tales como comisarios y sus subalternos; y aun incorporando a sacerdotes jesuitas a cargos dentro de la estructura institucional de la Inquisición.

En otro orden de conclusiones, pudimos definir también que la Inquisición fue un aparato judicial de exclusivas características modernas, brazo penal de una Monarquía que hacía uso de la religión católica para centralizar en la figura del monarca la suma del poder total en el imperio más extenso y rico de aquél tiempo. Tal como

problemáticas bien distintas a las del contexto español. José Eduardo Franco señala dos etapas bien diferenciadas en la relación jesuitas-Santo Oficio portugués: La primera, que abarca desde la fundación de la Orden a mediados del siglo XVI y hasta la independencia de 1640, caracterizada por una relación sin grandes tensiones y con escasa cooperación acción mutua. La segunda, a partir de la independencia portuguesa, con una tensión creciente entre ambas instituciones, fruto en gran medida de un creciente “antijeusuitismo liberal, republicano y de filiación pombalina" (Franco, 2015, p. 11). 
sostiene una unánime opinión al respecto, la Inquisición fue una institución nefasta, a través de cuyos discursos de poder y la criminalización de las prácticas heterodoxas al catolicismo sirvió también, como apunta Escudero, en “...una pieza clave en la administración del Estado del Antiguo Régimen" (2005, p. 62). Pues se produjo desde fines del siglo XVI una alianza entre la Iglesia y la Monarquía con el objeto de dominar amplios territorios; mientras que la herejía fue precisamente la resistencia a este poder de la Iglesia.

En América, el clero diocesano adquirió un extraordinario protagonismo. Del mismo modo, el Patronato Real intenta limitar la acción de las órdenes regulares, algo por lo que accionan juntos la Inquisición y los virreyes (como la amistad de Cerezuela y Toledo), aunque luego tengan conflictos de competencia. Aun así, la Iglesia mantuvo criterios del Antiguo Régimen respecto de la organización social, apoyando el orden estamental, en el intento de convertirse en un poder dominante a todos los Estados, controlando desde la doctrina a los individuos y, sobre todo, a la familia. Estableciendo cómo debían ser las relaciones sociales, fortaleciendo su poder a través de un discurso normativo-represivo y con una alta visibilidad; en la búsqueda del disciplinamiento social para gobernabilidad de sus vastos dominios. En cuyo campo de acción las diferentes estrategias de dominación se basaron sobre un delicado sistema de equilibrio de poderes; principio éste que actuaba tanto al interior de las instituciones como de la sociedad misma. Esfuerzo éste de la Monarquía que tuvo como estrategia aplicar su justicia inquisitorial hasta en las regiones más periféricas del Imperio, como parte de un control social unificado.

Desde el último cuarto del siglo XVI hasta 1616 es un tiempo que se abre en simultáneo con la instauración del Tribunal del Santo Oficio en el Perú, hecho efectivo en 1570, así como con la fundación de Córdoba del Tucumán tres años después. Poco más de cuarenta años en que Córdoba y las restantes ciudades de la Gobernación del Tucumán compartieron un solo Comisario 'general' de la Inquisición, y que coincidía además con la jurisdicción diocesana. Radicado en Santiago del Estero, este ministro manejaba toda la justicia inquisitorial con arbitrio general para toda la región. Época ésta marcada por una justicia inquisitorial débil, dependiente de la Real Hacienda y que no alcanza a efectivizar las intenciones del Tribunal limeño ni de la Corona en esta región de reciente conquista e implantación de la estructura colonial española. Momento en que casi no hay registro de persecución a conversos y en donde abundan los casos contra frailes y clérigos 'solicitantes'. Justicia de limitado alcance que, sin embargo, sirvió como instrumento de poder para múltiples actores y grupos sociales de este escenario.

Ha sido éste un largo siglo XVII para Córdoba, que comienza en 1573, con la fundación de la ciudad, y finaliza en 1699 con el traslado a ella de la diócesis del Tucumán. Siglo de formación y primer desarrollo en un espacio de carácter mestizo, a través del intercambio y el sincretismo cultural en un nuevo universo social, bajo un orden político-económico de dominación colonial. Tiempo también en que el Tribunal de Santo Oficio de la Inquisición, con sede en Lima, intentó imponerse sobre la población de las Gobernaciones al sur del Perú, actuando como un instrumento de doble dominación, por parte de la Iglesia Católica y del Estado Imperial español de los Austrias; participando activamente en la formación social de estos territorios en los confines del Imperio.

En un tiempo en que la condición jurídica que los españoles les impusieron a las poblaciones indígenas conquistadas aun no estaba clara, estos aparecen en acusaciones 
sobre herejía, algo que tendrá un contrapeso con la Bula Omnímoda de 1522 (Greenleaf, 1992, p. 17), que de algún modo abrió a la puerta a América de todas las órdenes religiosas regulares y a través de cuya actividad de evangelización y de las llamadas "extirpación de Idolatrías", la dirección 'espiritual' de los indios se convirtió en un espacio ajeno a la jurisdicción inquisitorial. Por otra parte, la Inquisición era, por concepto, un Tribunal que juzgaba a cristianos que incurriesen en alguna acción considerada por el Santo Oficio como herejía; y no a individuos que no habían sido evangelizados y practicaban aún otra religión. En tanto pueblos conquistados y parte ya del Imperio español, como súbditos del rey los indios debían convertirse al cristianismo, pero no ser perseguidos con la Inquisición por no serlo.

Tras la conquista del Imperio de los Incas por los españoles, se instaló en el Virreinato del Perú el mismo ejercicio de los obispos sobre la justicia inquisitorial, quienes ejercieron, "por sí o sus delegados, la correspondiente jurisdicción en cosas y casos del Santo Oficio" (Medina, 1914, p. 17). Sin embargo, tras la experiencia novohispana y los argumentos de De Las Casas en disputa para todo el continente, la inquisición ordinaria del Perú no actuó contra las poblaciones indígenas sino más bien contra un nuevo sector social, propio de ese tiempo y ese espacio: los tardíos conquistadores de la América meridional. Impulsados por virreyes y gobernadores, durante los primeros cincuenta años del virreinato peruano, los obispos nombrados por Patronato Real utilizaron la jurisdicción penal de la 'inquisición ordinaria' para perseguir aquéllos aventureros que, en palabras de Medina llegaron en tropel al antiguo Imperio de los Incas, y cuando ya éste no bastó para saciar su codicia, poseídos siempre de la sed del oro y del espíritu de descubrir y conquistar nuevas y maravillosas tierras, lanzáronse en bandadas a los cuatro vientos" (Medina, 1945, p. 15). Estos tardíos conquistadores presentan un perfil que de algún modo visibiliza vínculos de larga duración braudelianas, que habrían unido la mentalidad de los Romances tardomedievales con el avance de la conquista en América (Baschet, 2009). Con estímulo de aquél que viene a 'valer más', estos individuos mostraron una clara intención de convertirse en dueños de latifundios y señores de la mano de obra que ofrecían las tierras al sur del Perú. Mientras que la persecución de estos hombres por parte de la Iglesia y de la Corona, a través de los instrumentos otorgados por la justicia inquisitorial episcopal, son el reflejo de la transformación mundial que, en términos de la constitución de un poder absoluto e imperial basado en el mercantilismo global, fue transformándose desde la atomización feudal a la centralización del naciente Estado moderno.

Afirma Serrera y González, que la política de Toledo fue expulsar del Perú a la soldadesca de Pizarro y Almagro y aprovechar para conquistar y poblar las tierras al sur del virreinato (2011). Pero lo cierto es que para alcanzar este objetivo puso todo su esfuerzo en desarticular el poder de conquistadores y adelantados, del mismo modo que el de numerosos clérigos y frailes que, utilizando su condición de autoridad religiosa, se beneficiaban de la falta de control de la Iglesia en estos territorios alejados de los principales centros del poder colonial.

Y el Tucumán del siglo XVI fue escenario principal de los conflictos entre las huestes de conquistadores y las autoridades Reales y eclesiásticas del Virreinato. Y, ciertamente, el caso más significativo de esta época es la persecución al fundador de la Serena en Chile y de Santiago del Estero en el Tucumán, Francisco de Aguirre (15001581). 
La causa está conformada por los tres procesos inquisitoriales seguidos contra este conquistador español, sólo el último de los cuales se sustanció ya establecido el Tribunal del Santo Oficio en Lima. Estos procesos contra conquistadores y militares de las últimas conquistas al sur del Perú muestran el profundo vínculo de poder entre el gobierno imperial y la Iglesia, que encontró en la justicia inquisitorial un instrumento de dominación, represión y control inapelable sobre individuos que no respondían a los intereses del Imperio y del Catolicismo. Este proceso de asimilación entre ambas esferas de poder se hará más evidente tras la fundación del Tribunal del Santo Oficio de Lima en 1569, con actuación desde 1570, y la incorporación de nuevos actores a la trama geopolítica de aquél territorio aún indómito, como los miembros de la Compañía de Jesús y la avanzada portuguesa desde el Brasil y la cuenca rioplatense.

\section{Referencias Biográficas}

Archivo Municipal (1882). Libro primero de las Actas del Cabildo de Córdoba. Córdoba: Establecimiento Tipográfico "La Carcajada".

Avella, Ch. (1944). Los clérigos Salcedo en el Tucumán del siglo XVI. Archivum, Revista de la Junta de Historia Eclesiástica Argentina; Tomo II, c.1. Buenos Aires.

Ayrolo, V. (2007). Funcionarios de Dios y de la república. Buenos Aires: Biblos.

Baschet, J. (2009). La civilización feudal. Europa del año mil a la colonización de América. México: FCE.

Bataillon, M. (2014). Los jesuitas en la España del siglo XVI. México: FCE-Junta de Castilla/León.

Bixio, B. y González Navarro, C. (2003). Práctica de la justicia y resistencia indígena: Córdoba del Tucumán, siglos XVI y XVII. Colonial Latin American Historical Review, vol. 12. New Mexico.

Cabrera, P. (1934). Introducción a la Historia Eclesiástica del Tucumán, tomo I. Buenos Aires: Librería Sta. Catalina.

Cárcano, R. (1929). Primeras luchas entre la Iglesia y el Estado en la Gobernación del Tucumán, Siglo XVI. Buenos Aires: Junta de Historia y Numismática.

Catalán, E. (1926). La brujería penada con la hoguera en el Tucumán colonial. Revista de criminología, psiquiatría y medicina legal. Año XIII, $N^{\circ} 76-77$, jul-ago y septoct. Buenos Aires.

Escudero, J. A. (2005). Estudios sobre la Inquisición. Madrid: Colegio Universitario de Segovia, Marcial Pons, Ediciones de Historia.

Franco, L. E. (2015). A Companhia de Jesus e a Inquisicao: afectos e desafectos entre duas institucoes influentes (Séculos XVI-XVII). Actas do Congreso Internacional Atlántico de Antiguo Régime: poderes e sociedades.

Furlong Cardiff SJ, G. (1946). Los jesuitas y la cultura rioplatense. Buenos Aires: Huarpes.

Gracia SJ, J. (2006). Los jesuitas en Córdoba. Córdoba: EDUCC. 
Greenleaf, R. E (1992). Zumárraga y la inquisición mexicana. 1536-1545. México: FCE.

Lesser, R. (2012). Personajes: Fray Francisco de Vitoria. Historias con Lupa. Buenos Aires.

Levillier, R. (1918). Santiago del Estero en el Siglo XVI. Madrid.

(1919). Organización de la Iglesia en el Perú en el siglo XVI. Madrid.

- (1926). Papeles eclesiásticos del Tucumán, vol. I. Madrid.

Lewin, B. (1939). El judío en la época colonial. Un aspecto de la Historia Rioplatense. Buenos Aires: Colegio Libre de Estudios Superiores.

Lozano SJ, P. (1755). Historia de la Compañía de la Jesús de la Provincia del Paraguay, I. c XVI, N7. Madrid.

Martínez Ruiz, B. y Cerviño, R. A. (1962). Hernán Mejía Miraval o la conquista del Tucumán. Tucumán: Cuadernos de Humanitas.

Mateos, F. (1970): Sínodos del Obispo del Tucumán, Fray F. de Trejo y Sanabria (1579, 1606 y 1607). Missionalia Hispánica. Madrid.

Lisi, F. L. (1990). El Tercer Concilio Limense y la aculturación de indígenas sudamericanos. Salamanca: Universidad de Salamanca.

Maeder, E. (1996). Aproximación a las misiones guaraníticas. Buenos Aires: Ed. de la Universidad Católica Argentina.

Medina, J. T. (1914). La primitiva Inquisición Americana. Estudio Histórico. Santiago de Chile: Imprenta Elzeviriana.

(1945). El Tribunal del Santo Oficio de la Inquisición en las Provincias del Plata. Buenos Aires: Editorial Huarpes.

Moyano Aliaga, A. (2003). Don Jerónimo Luis de Cabrera (1528-1574). Origen y descendencia. Córdoba: Alción Editora.

Muñoz Moraleda, E. (1999). Presencia de Francisco de Victoria, primer obispo del Tucumán, en la monarquía hispánica de Felipe II (1580-1592). Historia y Humanismo; IHE, núm. 99-1553.

Page, C. A. (2017). Una biogradía del jesuita Marciel de Lorenzana. Precursor de las misiones del Paraguay escrita por el P. Diego de Boroa. Córdoba: CIECS, Báez Ed.

Palomeque, S. (dir.) (2005). Actas del Cabildo Eclesiástico. Obispado del Tucumán con sede en Santiago del Estero 1592-1667. Córdoba: Ferreyra Editor.

Piana, J. (1992). Los indígenas de Córdoba bajo el régimen colonial, 1570-1620. Córdoba: UNC.

Piana, J. y Sartori, F. (2012). 1610: El Colegio Máximo de la Compañía de Jesús en Córdoba. La construcción de un falso histórico. Córdoba: EDUCC-Centro Paraquaria. 
Ramos, G. y Urbano, H. (1993). Catolicismo y Extirpación de Idolatrías. Siglos: XVIXVIII. Cuzco: Centro de Estudios Regionales Andinios 'Bartolomé de las Casas'.

Sartori, F. (2015). Tan a banderas desplegadas. El poder de un comisario Inquisitorial americano del siglo XVII. CLAR (Colonial Latin American Review); vol. 24, $n^{\circ}$. Cambridge University Press.

Segreti, C. (1973). Córdoba, ciudad y Provincia (Siglos XVI-XX). Según relatos de viajeros y otros testimonios. Córdoba: Junta Provincial de Córdoba.

Serrera y González, R. (2011). La América de los Habsburgo (1517-1700). Sevilla: Universidad de Sevilla-Fundación Real Maestranza de Caballería de Sevilla.

Storni SJ, H. (1971). Catálogo 15. Id. "Documentos del P. Francisco de Angulo s.j. 1561-1575'. AHSI, 40.

Tedesco, É. y Crouzeilles, C. (2005). El cabildo eclesiástico de Santiago del Estero. Estructura eclesiástica y formación histórica (Siglo XVII). En: Palomeque, Silvia (Dir.). Actas del Cabildo Eclesiástico. Obispado del Tucumán con sede en Santiago del Estero 1592-1667. Córdoba: Ferreyra Editor. 